\title{
MATROMORPHY IN NICOTIANA RUSTICA
}

\author{
D. S. VIRK, S. J. DHAHI and R. J. BRUMPTON \\ Department of Genetics, University of Birmingham, Birmingham B15 2TT, England
}

Received 24.i.77

\section{SUMMARY}

\begin{abstract}
The possibility of obtaining instant pure-breeding lines by matromorphic seed development in $\mathcal{N}$. rustica has been investigated. Maternal parents homozygous for recessive marker genes and heterozygous for dominant marker genes were pollinated with different Nicotiana species and with irradiated pollen of a $\mathcal{N}$. rustica variety having a dominant marker. Pollinations with 65 species and with irradiated varietal pollen receiving doses ranging from 8 to $40 \mathrm{kr}$ $\mathrm{X}$ - and gamma rays were performed on as many as 40 maternal genotypes. Promising matromorphic progenies were studied for the segregation of marker genes and several quantitative characters and for cytological abnormalities in the first and second generations following their induction. Of the numerous pollinations only one homozygous diploid maternal was recovered from $F_{1}$ $(\mathrm{V} 5 \times \mathrm{Vl})$ maternal parent pollinated with $\mathcal{N}$. langsdorffi $(2 n=18)$. Pollinations with $\mathcal{N}$. langsdorff, however, consistently and frequently induced haploids or near haploids. The evidence gathered over many years of experimentations throws serious doubt on the possibility of using matromorphy as an alternative method of producing pure-breeding lines in $\mathcal{N}$. rustica.

Transfer of a dominant marker gene from the irradiated pollen to a triple recessive maternal parent has prospective applications in the production of isogenic lines as an alternative to recurrent backcrossing.
\end{abstract}

\section{INTRODUGTION}

FOR many years plant breeders and geneticists have been attempting to find methods which would shorten the time requirements of the conventional procedures for producing pure-breeding lines by inbreeding. One such alternative approach relies on the occurrence of non-hybrid matromorphic diploid offsprings which originate entirely from the maternal parent. During the induction of matromorphs, egg fertilisation does not take place in spite of pollination often being essential for providing the stimulus for the maternal seed to develop. Even where the male nucleus penetrates the egg apparatus it aborts soon afterwards.

The occurrence of homozygous maternals which have probably arisen by the doubling of the maternal haploid gametes has been reported by many workers in a number of crop plants (for example, Noguchi, 1928; Terao, 1934; U, 1935; Mohammad and Sikka, 1940; Olsson, 1960; Röbbelen, 1966; Abdalla and Hermsen, 1972). On the other hand, Tokumasu (1965), Mackay (1972) and Eenink (1974a, b, c, $d$ and $e$ ) reported only heterozygous maternal seed which probably arose by diploid parthenogenesis (see Mackay, 1968 and 1972; Eenink, 1974a, b, c, $d$ and $e$ for review). There is, therefore, disagreement in the literature about the heterozygous or homozygous nature of the maternal seed and hence the value of this approach in plant breeding. The occurrence and nature of matromorphs has, therefore, been investigated in Nicotiana rustica where the availability of conventionally produced pure-breeding lines, suitable major gene markers, a wide 
choice of potential pollen parents and considerable information on the genetics of many continuously varying characters allow many more and less ambiguous tests to be performed than is usually the case.

\section{Materials ANd MEthods}

We have used two systems of inducing maternally produced progeny in Nicotiana rustica- (a) pollination by a different species of Nicotiana and (b) pollination with irradiated pollen of a $\mathcal{N}$. rustica variety and consistently hereinafter whether $(a)$ or $(b)$ pollinators are used their matromorphic progenies will be designated as $\mathrm{M}_{1}$ and $\mathrm{M}_{2}$ etc.

To rule out any contribution from the pollen parent in the maternally produced progeny $\left(\mathrm{M}_{1}\right)$ and to distinguish between homozygous and heterozygous progeny following either $(a)$ or $(b)$ types of pollination major gene markers were used. To cover all possibilities the varieties of $\mathcal{N}$. rustica used as maternal parents need to be of two types in respect of these markers - (i) homozygous for recessive marker genes and (ii) heterozygous for marker genes. Using (i) and either $(a)$ or $(b)$ pollinators carrying dominant marker genes we can detect the transmission of genetic material from the pollinator by screening for the dominant marker genes in the $M_{1}$ progeny. By using maternal parents of type (ii) we have a check on the homozygosity or heterozygosity of any maternally produced seed by examining the progenies of selfed $M_{1}$ plants $\left(M_{2}\right)$ for segregation of the marker gene. All progenies were large enough to guarantee a high probability of detecting a segregation if it occurred.

Additional supporting evidence can of course be obtained both in the $M_{1}$ and $M_{2}$ progenies by following the behaviour of the many quantitative characters for which maternal parents and pollinators differ and for which the heterozygous maternal parents of type (ii) would segregate on selfing. In the experiments using type (i) maternal parents the transfer of genetic material from the pollinator parents of type $(a)$ or $(b)$ was tested by comparing the means and variances of the $\mathrm{M}_{2}$ progenies with those of the maternal parents themselves. They can differ only if some transfer has occurred. Where the $(b)$ type pollinator was used the reciprocal backcrosses of the $\mathbf{M}_{1}$ plants to the maternal parents were also included in these comparisons. For type (ii) maternal parents the variances within the $\mathrm{M}_{2}$ progenies were compared with those of the pure-breeding parents of the $\mathbf{F}_{1}$ maternal parents or conventionally derived pure-breeding lines from the same cross. Again the variances are expected to be the same unless the $M_{1}$ plants are heterozygous. For making these comparisons single plant randomisation with family sizes ranging from 30 to 50 sibs were used and a minimum of three and up to eight continuously varying characters were recorded.

Cytological observations on root tips and floral buds of the $M_{1}$ and $M_{2}$ progenies were used wherever possible to obtain additional information on the status of maternal progenies. These are more powerful if a type $(a)$ pollinator is used which differs in chromosome complement from the maternal parents.

Maternal parents of type (i) were drawn from the Birmingham Nicotiana rustica collection of 32 varieties which carry many marker genes. Seven varieties, V14, V27, V34, V72, V73, V75 and V80 which comprise group 
(i.l) have the three recessive characters-yellow ovaries, mophead and yellow-green plant parts; 21 varieties which comprise group (i.2) have green ovaries either mop or non-mopheads and green plant parts; and four varieties which comprise group (i.3) have dominant characters-black ovary, non-mophead and green plant parts. Ovary colour is controlled by duplicate genes at two loci with three alleles so that black is epistatic to green and yellow while green is epistatic to yellow. Mophead is a compact type of inflorescence and is recessive to the looser non-mophead type while green plant colour is dominant to yellow. The type (ii) maternal parents were eight $F_{1}$ 's between groups (i.2) and (i.3) parents and were therefore heterozygous for ovary colour and in some cases type of inflorescence also. Pollinators of type $(a)$ were all green ovaried except for Nicotiana undulata which is black while the type $(b)$ pollinator was Vl2 which belongs to group (i.3).

The attempts to induce matromorphs with pollen from different species (type-a) were commenced during 1969-70 when 13 species, all fairly closely related to the progenitors of $\mathcal{N}$. rustica, were used to pollinate V27 and V75 which are maternal parents of type (i.l) and reciprocal $F_{1}$ 's of VI and V5 which are maternal parents of type (ii). All $\mathbf{M}_{1}$ plants with the triplc recessive phenotype like their (i.l) maternal parents from the former and both black and green ovaried plants with a rustica-like phenotype from the latter were selfed to produce $\mathrm{M}_{2}$ progenies which were evaluated during 1973. Of these 13 species, only one $\mathcal{N}$. langsdorffii $(2 n=18)$ appeared to be a successful inducer as judged by these tests. It was therefore used to pollinate all the 32 varieties of type (i.1), (i.2) and (i.3) and eight reciprocal $F_{1}$ 's of type (ii) during 1973. After examining the $\mathbf{M}_{1}$ progenies the $\mathbf{M}_{2}$ progenies of the most promising were also studied. Meanwhile a sample of 52 Nicotiana species were obtained from the John Innes Institute, Norwich, U.K. and from the Tobacco Research Laboratory, Oxford, North Carolina, U.S.A. in order to identify other potential inducers. Two varieties V27 and V80 representing maternal parents of type (i.l) and possessing all the recessive markers were used during the 1976 pollination programme. Pollinations were, however, possible for only 25 species because of the different agroclimatic requirements of the other species.

Control emasculations were made on all genotypes used as maternal parents without subsequent pollination to see if any seed was produced by spontaneous parthenogenesis. None was, however, produced.

Variety 12 which is homozygous for the dominant black ovary, nonmophead and green plant (type 1.3) marker genes was chosen as the pollen parent for all pollinations made with irradiated pollen. The aim was to damage the pollen grains to the extent that they were still capable of germination but incapable of effecting fertilisation. Doscs of X-rays from $500 \mathrm{r}$ to $10 \mathrm{kr}$ at intervals of $500 \mathrm{r}$ were applied and eight maternal parents all of which were homozygous for the yellow or green, recessive ovary colour marker and some for the recessive mophead and yellow plant marker genes also, were pollinated. Pollen treatment with higher doses of both $\mathrm{X}$ - and gamma ray radiation ranging from $15 \mathrm{kr}$ to $40 \mathrm{kr}$ at $5 \mathrm{kr}$ intervals was used for pollinating either V7 and V27 homozygous for green and yellow ovaries or $F_{1}(\mathrm{~V} 5 \times \mathrm{Vl})$ heterozygous for black green ovaries. The $\mathrm{M}_{1}$ progenies from these pollinations were screened for suspected maternals and mutants. The $\mathbf{M}_{2}$ progenies of the suspected $\mathbf{M}_{1}$ maternals were raised along with $39 / 2-\mathrm{G}$ 
the reciprocal backcrosses of the $M_{1}$ 's to their maternal parent. The mutants were isolated for their possible value as new markers in the varietal collection. All other plants were discarded.

\section{Results AND Discussion}

The frequency and type of $M_{1}$ families obtained from interspecific pollinations and from pollinations made with irradiated pollen are presented in table 1.

TABLE 1

A summary of the types of $\mathrm{M}_{1}$ individuals obtained from interspecific pollinations and from pollinations with irradiated pollen

(a) Interspecific pollinations

(i) Homozygous maternal parents
1. V27 $\times$ N. langsdorffii
2. V27 $\times N$. langsdorffi (repcat)
3. Colchicine treated (2)
4. V75 $\times N$. langsdorffii
5. Other 30 varieties $\times N$.
langsdorffii
6. V27 $\times$ N. stenocarpa
7. V27 and V80 $\times 25$ other species

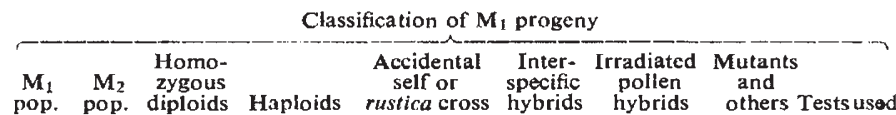

(ii) Heterozygous maternal plants

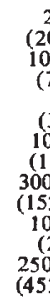

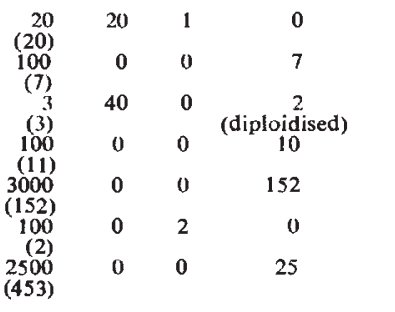

$\begin{array}{rlll}0 & 0 & 0 & \mathrm{~m}, \mathrm{q}, \mathrm{cy} \\ 0 & 0 & 0 & \mathrm{~m} \\ 1 & 0 & 0 & \mathrm{~m} \\ 0 & 0 & 0 & \mathrm{~m} \\ 0 & 0 & 0 & \mathrm{~m} \\ 0 & 0 & 0 & \mathrm{~m} \\ 428 & 0 & 0 & \mathrm{~m}\end{array}$
1. $\mathrm{F}_{1}(\mathrm{~V} 5 \times \mathrm{V} 1) \times N$. langsdorffii
2. Other $7 \mathrm{~F}_{l}$ 's $\times N$. langsdorffi
3. $\mathrm{F}_{1}(\mathrm{~V} 1 \times \mathrm{V} 5) \times N$. debneyi
4. $\mathrm{F}_{1}(\mathrm{~V} 2 \times \mathrm{V} 12) \times N$. suaveolens
5. $F_{1}(\mathrm{~V} 12 \times \mathrm{V} 2) \times N$. suaveolens

(b) Pollinations with irradiated V12 pollen

(i) Homozygous maternal parents

1. V5 $\times$ V12 (X-rays $9 \mathrm{kr}$ )

2. $\mathrm{V} 7 \times \mathrm{V} 12$ (X-rays $10 \mathrm{kr}$ )

3. V14 $\times$ V 12 (X-rays 8 and $9 \mathrm{kr}$ )

4. $\mathrm{V} 7 \times \mathrm{V} 12$

a. X-rays $15,20,25$,

b. gamma rays $15,20,25$,

5. $\mathrm{V} 27 \times \mathrm{V} 12$

a. X-rays 15, 20, 25,

$30+35+40 \mathrm{kr}$

b. gamma rays $15,20,25$,

\begin{tabular}{|c|c|}
\hline 100 & 50 \\
\hline $\begin{array}{l}87) \\
700\end{array}$ & 0 \\
\hline $\begin{array}{l}\text { (62) } \\
92\end{array}$ & 3716 \\
\hline $\begin{array}{l}(92) \\
150\end{array}$ & 0 \\
\hline $\begin{array}{l}(22) \\
150 \\
(37)\end{array}$ & 150 \\
\hline
\end{tabular}

86
62
0
0
0

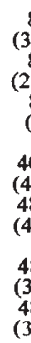

150 330

0

0

$?$
0
0
1
0
$?$
0

0

$\begin{array}{llll}0 & 1 & 36 & \mathrm{~m}, \mathrm{q}, \mathrm{cy} \\ 0 & 3 & 17 & \mathrm{~m}, \mathrm{q}, \mathrm{cy}\end{array}$

(ii) Heterozygous maternal parents

$\begin{array}{crrrrrrr}1 . F_{1}(V 1 \times V 5) \text { and } F_{1}(V 5 \times V 1) & 480 & 75 & 0 & 0 & 0 & 0 & 113 \\ \times V 12 \text { gamma rays } 15 \text { and } & (117) & & & 411\end{array}$

$\mathrm{s}=$ single gene transfer, $\mathrm{m}, \mathrm{q}$, cy refer to marker gene, quantitative and cytological tests. Parentheses indicate the number of $\mathbf{M}_{1}$ plants which were successfully raised. 


\section{(a) Interspecific pollinations}

\section{(i) Homozygous maternal parents}

The $M_{1}$ progeny of $V 27 \times \mathcal{N}$. langsdorffi met all the criteria for a purely maternal origin having the triple recessive phenotype and the chromosomal complement of $\mathcal{N}$. rustica $(2 n=48)$ and not that of a hybrid with $\mathcal{N}$. langsdorffi $(2 n=18)$. The $\mathbf{M}_{2}$ progenies supported these conclusions in that the means and within family variances of the $M_{2}$ progenies for three quantitative characters did not differ significantly from those of the maternal parent V27. For instance, for height at flowering the variance between the two means was 4.52 ( 1 d.f.) as against an error variance of 4.57 (36 d.f.) and the within family variances were 4.93 (18 d.f.) and 4.22 (18 d.f.) for matromorphic and V27 families, respectively.

On the basis of this evidence all the 32 inbred genotypes in the rustica collection were pollinated with $\mathcal{N}$. langsdorffi. The $\mathbf{M}_{1}$ progenies of all these pollinations, including a repeat with $\mathrm{V} 27$, consistently produced miniature plants which grew no more than $5 \mathrm{~cm}$ in size. Because of their growth habit and the lack of dividing cells, cytological investigations of these plants were unsuccessful but that these plants were haploid or near haploid was indicated when two of the three $M_{1}$ plants from V27, following treatment with $0 \cdot 01$ per cent colchicine solution for 24 hours, gave $\mathbf{M}_{2}$ progenies in which every plant had the triple recessive phenotype of the V27 maternal plant. The third $\mathrm{M}_{1}$ plant treated in this way, however, proved to be heterozygous for dominant markers from the pollen parent. This raises the possibility that the miniature $M_{1}$ plants arose by selective chromosome elimination of part or all of the male complement from an interspecific hybrid rather than by haploid parthenogenesis. A high frequency of barley haploids was recovered by Subrahmanyam and Kasha (1973) following the selective elimination of the whole chromosomal complement of the tetraploid $H$. bulbosum in the zygote produced on a diploid $H$. vulgare female. The occurrence of this process has also been reported in interspecific crosses between $\mathcal{N}$. tabacum and $\mathcal{N}$. plumbaginifolia by Ar-rushdi (1957), and Davies (1974) has discussed the mechanisms of selective elimination of $H$. bulbosum and $\mathcal{N}$. plumbaginifolia chromosomes in these crosses.

There was only a single instance of a normal $M_{1}$ plant from a $\mathcal{N}$. langsdorffii pollination of V75 (a (i) 4 in table 1), and this had the green ovary phenotype which differs from that of its maternal parent. The high seed set of this plant was incompatible with a species hybrid origin and contamination remains the only reasonable explanation. The $\mathbf{M}_{1}$ progenies from pollinations of V27 and V80 (type i.1) maternal parents by the other 25 species were either interspecific hybrids or they had abnormal phenotypes and were probably aneuploids with the exception of two plants from the V27 $\times \mathcal{N}$. stenocarpa cross which had the triple recessive phenotype of the maternal parent. The maternal origin of these two exceptional plants can not be distinguished from the possibility of an accidental self pollination without further investigation of this cross.

\section{(ii) Heterozygous maternal parents}

The $\mathrm{M}_{1}$ progeny of $\mathrm{F}_{1}(\mathrm{~V} 5 \times \mathrm{V} \mathrm{l}) \times \mathcal{N}$. langsdorffi ((ii) 1 in table 1$)$ produced miniature plants with the exception of one black ovaried normal plant whose $\mathrm{M}_{2}$ progeny did not segregate for the major gene or for any of seven 
quantitative characters. The within-family variances of the parental inbreds (V1 and V5) of the $F_{1}$ maternal parcnt and of the matromorphic $M_{2}$ progenies for the two developmental heights $\left(\mathrm{H}_{2}\right.$ and $\left.\mathrm{H}_{3}\right)$, height at flowering (HFT), flowering time (FT), length and width of the largest leaf (LL and LW) and final height $(\mathrm{FH})$ are given below:

\begin{tabular}{lcccccccc}
\multicolumn{1}{c}{ Genotype } & d.f. & $\mathrm{H}_{2}$ & $\mathrm{H}_{3}$ & HFT & FT & LL & LW & FH \\
V1 & 49 & $73 \cdot 45$ & $79 \cdot 10$ & $46 \cdot 56$ & $4 \cdot 78$ & $3 \cdot 11$ & $4 \cdot 08$ & $50 \cdot 63$ \\
V5 & 49 & $30 \cdot 47$ & $51 \cdot 32$ & $59 \cdot 04$ & $1 \cdot 48$ & $3 \cdot 79$ & $3 \cdot 17$ & $56 \cdot 77$ \\
Matromorph $\left(\mathrm{M}_{2}\right)$ & 48 & $27 \cdot 32$ & $67 \cdot 02$ & $33 \cdot 07$ & $3 \cdot 48$ & $2 \cdot 41$ & $3 \cdot 02$ & $57 \cdot 18$
\end{tabular}

In no case does the variance of matromorphic progeny exceed that of the parental inbred with the larger variance and for $\mathrm{H}_{2}$ and HFT the variances do not differ from those of the parental inbred with the smaller variance. This one plant therefore met all the requirements of a matromorphic origin involving automixis or endomitosis. In automixis diploid plants can arise from the fusion of the two cells of the immediate product of meiosis or by the fusion of two haploid nuclei within the embryo sac. In the former, however, the result depends upon the position of any cross-over relative to the marker gene and hence on the nature of the rcduction process, prereduction or post-reduction. Homozygous plants are only expected if prereduction is involved. Fndomitosis involves the doubling of the reduced maternal gametes leading to diploid homozygotes. We can, however, safely rule out possibilities like diploid androgenesis, adventitious embryony producing only heterozygous $M_{1}$ plants and truc hybridisation. All the $\mathbf{M}_{1}$ progenies of the other seven $\mathrm{F}_{1}$ maternal parents pollinated with $\mathcal{N}$. langsdorffi $i$ behaved similarly producing only miniature plants.

The $\mathrm{M}_{1}$ progeny of $\mathrm{F}_{\mathbf{1}}(\mathrm{VI} \times \mathrm{V} 5) \times \mathcal{N}$. debneyi consisted of equal numbers of plants with black and green ovaries. The black ovaried plants all gave $3: 1$ segregation ratios of black to green in their $\mathbf{M}_{2}$ progenies together with significant segregation for three quantitative traits. 'These results are compatible with the $\mathbf{M}_{1}$ plants being interspecific hybrids. The cytological examinations could add little to this conclusion because both species had the same chromosome number $(2 n=48)$.

Progenies of reciprocal $\mathrm{F}_{1}$ 's of $\mathrm{V} 2$ and $\mathrm{V} 12$ pollinated with $\mathcal{N}$. suaveolens produced robust sterile interspecific hybrids in the $M_{1}$ generation except for three abnormal rustica like plants all of which segregated for seven. quantitative characters in their $\mathrm{M}_{2}$ progenies. One of these $\mathrm{M}_{1}$ plants was, however, homozygous for the dominant marker gene. Homozygosity at one major gene locus can be cxplained if this plant originated via diploid parthenogenesis and the locus was situated between the centromere and proximal chiasma. Should the sccond division therefore fail to form a restitution nucleus the result would be homozygosity for all loci between the cross-over point and the centromere, but heterozygosity for any loci beyond the cross-over point. We cannot, however, on the evidence available rulc out the possibility of the accidental selfing of the matcrnal $F_{1}$ parent. Nevertheless, none of the 40 maternal parents, whether homozygous or heterozygous, produced any secd following control cmasculations. This rules out spontancous parthenogenesis in $\mathcal{N}$. rustica as well as showing that accidental pollination, selfing or contamination if they occur at all, are at a very low frequency. 


\section{(b) Pollinations with irradiated pollen}

\section{(i) Homozygous maternal parents}

Of the numerous pollinations with pollen of V12 irradiated with X-and gamma rays only four $M_{1}$ plants were suspected of being solely maternal in origin (b. I and 2 in table I). However, their $\mathrm{M}_{2}$ and backcross progenies showed significant segregation for eight quantitative characters and contained abnormal segregants. In general, therefore, the radiation damaged pollen contributed to the $\mathrm{M}_{1}$ progenies.

All of the $M_{1}$ progenies of yellow ovaried maternal parents pollinated with irradiated pollen of black ovaried parent had black ovaries but they had the recessive yellow plant phenotype of the V27 maternal parent for $15 \mathrm{kr} \mathrm{X}$ - and gamma ray doses. The $\mathrm{M}_{2}$ progenies of these plants segregated for the black and yellow ovary and hence their $M_{1}$ parents were heterozygous at this locus. These results are compatible with single gene transfers from the pollen parent. They also show that yellow ovary and yellow plant are controlled by independent mutational sites. Independent evidence of single gene transfers in Nicotiana has recently been presented by Pandey (1975). According to Pandey (1975) the radiation of pollen pulverises the generative nucleus to produce a mass of fine chromatin. This leads to a false fertilisation which results in the division of the egg but the disorganised mass of pollen chromatin prevents a normal first zygotic division. However, normal mitotic division occurs since the chromatin fragments are subsequently lost. The overall result is a parthenogenetically produced diploid embryo. Occasionally the fragments of the disorganised chromatin may associate with their homologues among the egg chromatin. During further replication, substitution or addition may occur. Depending upon the pairing with or without attachment of the fragment as an exosome the substitution, addition or substitution plus addition can be heterozygous or homozygous.

\section{(ii) Heterozygous maternal parents}

Contributions from irradiated pollen were apparent in the $M_{1}$ and $M_{2}$ progenies of seeds produced on $F_{1}$ maternal parents and these investigations added nothing new to those carried out with homozygous maternal parents (see table l, b (ii)).

\section{Conclusions}

The practical utility of using matromorphic seed development as an alternative method of producing pure-breeding lines depends upon the induction of homozygotes. Of the numerous pollinations of homozygous and heterozygous maternal parents with pollen from different species and with irradiated pollen in the present study only one $M_{1}$ plant from an $F_{1}$ $(\mathrm{V} 5 \times \mathrm{Vl})$ maternal parent pollinated by $\mathcal{N}$. langsdorffi met all the requirements of a homozygote of maternal origin. The preliminary indications that such homozygotes could also be obtained from V27 maternal parent could not be repeated. Similarly, on the evidence available we were unable to rule out contamination as a possible explanation of the two $\mathrm{M}_{1}$ plants obtained from V27 following pollination with $\mathcal{N}$. stenocarpa which were homozygous for all the recessive markers of the V27 parent. Pollinations with the species $\mathcal{N}$. langsdorffii, however, consistently and frequently 
induced the production of $M_{1}$ miniature plants. These on treatment with colchicine gave either plants which bred as normal homozygous diploids with the phenotype of the maternal parent or segregated for marker genes from the maternal and pollen parents. These minature plants were, therefore, either maternal haploids or species hybrids. The former could be a possible source of homozygous maternal progeny.

In addition to being homozygous, diploids, to be useful matromorphs, should be inducible at a reasonably high frequency and easily and reliably identified and separated from other novel genotypes such as aneuploids, haploids, heterozygous maternals and true hybrids that can arise simultaneously in the $M_{1}$ progeny. Homozygosity of $M_{1}$ progeny in respect of a single gene marker only, in some cases at least may be misleading. In general, additional support must be obtained from independent markers or from the biometrical genetical analysis of several quantitative characters. For example, one black overiad $\mathrm{M}_{1}$ plant from $\mathrm{F}_{1}(\mathrm{~V} 12 \times \mathrm{V} 2)$ pollinated with $\mathcal{N}$. suaveolens was homozygous for ovary colour but was heterozygous for other traits. To distinguish between partial and complete homozygosity it is essential to use many, preferably linked and/or unlinked markers such as the ovary colour, plant colour and inflorescence types of markers used in our experiments and the 10 unlinked loci (one on each chromosome) used by Sarkar and Coe (1971) in their comparable studies of maize.

It has been shown that the $M_{1}$ progenies of homozygous and heterozygous maternal parents pollinated with irradiated pollen receiving $\mathrm{X}$ - and gamma ray doses ranging from $8 \mathrm{kr}$ to $40 \mathrm{kr}$ always contained contributions from the radiation-damaged pollen. Todua and Ternovskii (1973), however, reported a high frequency of homozygous diploid apomicitic plants in $\mathcal{N}$. tabaccum following a very low dose of $5.5 \mathrm{kr}$ gamma rays. Their conclusions were based on the recovery of recessive markers in the $M_{1}$, their stability in the $\mathbf{M}_{2}$ generation and on cytological tests that are not discriminating because the maternal parents and pollinators had the same chromosome number. Partial homozygosity in these apomicitic plants, of the kind obtained in our experiments, could only be distinguished from the complete homozygosity they claim if supporting evidence from several quantitative characters or additional major gene markers were available.

Matromorphy is of practical value only if maternal progeny can be induced on heterozygous maternal parents of typc (ii). However, as Mackay (1972) and Eenink (1974a, b, c, $d$ and $e$ ) have pointed out the recovery of heterozygous maternals should not be taken as evidence for the occurrence of this process, in spite of the numerous mechanisms that can be postulated for their origin, unless it can be confirmed on homozygous maternal parents of type (i) where tests for the absence of pollen parent contribution to the $\mathrm{M}_{1}$ progeny are relatively more efficient.

The results presented here have shown that the induction of maternal progeny docs not appear to be a viable proposition for producing instant, pure-breeding lines in Nicotiana rustica although the occurrence of maternal progeny in the Nicotiana genus has been reportcd by several authors from as early as 1910 (Goodspecd, 1954) and some species are known to contain genes that condition them to become facultatively apomicts. Our conclusions are, therefore, the same as those of Mackay (1972) after an equally careful investigation of the same phenomenon in Brassica.

An interesting outcome of our experiments is the confirmation that single 
genes can be transferred from irradiated pollen to the $\mathbf{M}_{1}$ progeny. This provides a possible rapid means of transferring specific desirable genes into the genetic background of an otherwise good variety which can normally be accomplished only by the time-consuming recurrent backcrossing. The production of isogenic lines which can be combined to develop a multiline variety might be greatly facilitated by this method.

Acknowledgments.-We are indebted to Professor J. L. Jinks for providing continuity of supervision and guidance over the long duration of these experiments and for his help and interest in the preparation of this paper.

\section{REFERENGES}

ABDALLA, M. M. F., AND HERMSEN, J. G. TH. 1972. Diploid parthenogenesis and androgenesis in diploid Solanum. Euphytica, 21, 426-431.

AR-RUSHDI, A. H. 1957. The cytogenetics of variegation in a species hybrid in Nicotiana. Genetics, 42, 312-325.

Davies, D. R. 1974. Chromosome elimination in inter-specific hybrids. Heredity, 32, 267-270

EENINK, A. H. 1974a. Matromorphy in Brassica oleracea L. I. Terminology, parthenogenesis in Cruciferae and the formation and usability of matromorphic plants. Euphytica, 23 429-433.

EENINK, A. H. 1974b. Matromorphy in Brassica oleracea L. II. Differences in parthenogenetic ability and parthenogenesis inducing ability. Euphytica, 23, 435-445.

EENINK, A. H. 1974c. Matromorphy in Brassica oleracea L. III. The influence of temperature, delayed prickle pollination and growth regulators on the number of matromorphic seeds formed. Euphytica, 23, 711-718.

EENINK, A. H. 1974d. Matromorphy in Brassica oleracea L. IV. Formation of homozygous and heterozygous diploid products of gametogenesis and qualitative genetical research on matromorphic plants. Euphytica, 23, 719-724.

EENINK, A. H. 1974e. Matromorphy in Brassica oleracea L. V. Studies on quantitative characters of matromorphic plants and their progeny. Euphytica, 23, 725-736.

goodspeed, T. H. 1954. The Genus Nicotiana, Chronica Botanica 16. Waltham, Mass.

MACKay, G. R. 1968. Possibilities from the use of matromorphy. Brassica meeting of Eucarpia, 11-18.

MACKAY, G. R. 1972. On the genetic status of maternals induced by pollination of Brassica oleracea with Brassica campestris. Euphytica, 21, 71-77.

mohammad, A., AND sikka, s. м. 1940. Pseudogamy in Brassica. Current Science, 9, 280-282. NoGuCHI, Y. 1928. Cytological studies on a case of pseudogany in the genus Brassica. Proc. Imp. Acad. (Tokyo), 4, 617-619.

orsson, G. 1960. Species crosses within the genus Brassica II-Artificial B. napus. Hereditas, $46,331-338$

PANDEY, K. K. 1975. Sexual transfer of specific genes without gametic fusion. Nature, 256, $310-313$.

RÖвBELEN, G. 1966. Beobachtungen bei interspezifischen Brassica-Kreuzungen, insbesondere über die Entstehung matromorpher $\mathrm{F}_{1}$-Pflanzen. Angew. Bot., 39, 205-221.

SARKAR, K. R., AND COE, E. H. JR. 1971. Origin of parthenogenetic diploids in maize and its implications for the production of homozygous lines. Crop Science, 11, 543-544.

SUBRAHMANYAM, N. C., AND KASHA, K. J. 1973. Selective chromosomal elimination during haploid formation in barley following interspecific hybridization. Chromosoma, 42, 111-125.

TERAO, H. 1934. Induction of parthenogenesis in interspecific pollinations and its practical meaning. Agri. Horti., Tokyo, 9, 1-10.

TODUA, v. A., AND TERNOvskiI, M. F. 1973. Induced diploid apomixis in Tobacco. Doklady Akad. Nauk SSSR, 211, 216-217.

rokumasu, s. 1965. On the origin of the matroclinous plants of $B$. japonica obtained from the cross between Brassica and Raphanus. 7. Jap. Soc. Hort., Sci., 34, 223-231.

u, N. 1935. Genome analysis in Brassica with special reference to experimental formation of B. napus and peculiar mode of fertilization. Jap. 7. Bot., 7, 389-452. 